\title{
EN TORNO AL ORIGEN DEL DINERO
}

\author{
DANIEL LAHOUD*
}

Carl Menger expuso en sus Principios de Economía Politica ${ }^{1}$ una explicación del origen del dinero que forma parte de las cuatro columnas sobre las que este economista basa su entendimiento de la Economía como ciencia. ${ }^{2}$ El texto aunque es señero, está poco difundido y a pesar de ello es criticado por otros economistas. Incluso algunos de los trabajos que vamos a reseñar no se refieren al libro, sino a un artículo que mantiene las ideas que originalmente publicó en los principios Éste documento se publicó en 1892 en Inglés, partiendo del original en Alemán (1871) en el Economic Journal. En dicho texto, Menger plantea que el dinero es producto de la selección natural, proceso que ocurre para resolver las complicaciones relacionadas al trueque debido a que éste último requiere la coincidencia de necesidades y está fundamentado en la valoración de uso ${ }^{3}$ de los bienes. Menger explica:

[...] los individuos únicamente tenían en cuenta, en sus intercambios, el valor de uso de los bienes y todas las operaciones se limitaban a aquellos casos en los que los bienes de que disponía un sujeto económico tenían para él menor valor de uso que los que

\footnotetext{
* Economista e historiador. Imparte docencia en las universidades Central de Venezuela y Católica Andrés Bello de Caracas.

1 Menger, C. (1871), Principios de Economía Política, Unión Editorial, 2.ㄹ ed., Madrid, 1997, pp. 319-337.

2 La referencia a las cuatro bases o ideas embrionarias del pensamiento de Menger son: la Utilidad Marginal decreciente, los Ordenes de la producción, la subestimación de las necesidades futuras ante las presentes y no menos importante ésta del Origen del dinero, que se enmarcan en la metodología deductiva y apriorística. Con base a todas ellas desarrolló sus Principios de Economía Política. Este y los documentos agrupados como Metodología de las Ciencias Sociales, son la propuesta seminal que se convertirá en lo que hoy llamamos Economía Austríaca.

${ }^{3}$ Se conoce como valor de uso a la utilidad que proporciona el bien al individuo que lo posee o busca cuando quiere un determinado bien.
} 
poseía el otro sujeto, mientras que para este segundo ocurriría todo lo contrario. A posee una espada que tiene para él menos valor de uso que el arado de B. Mientras que para B su arado tiene menos valor de uso que la espada de A. ${ }^{4}$

Debía haber estas coincidencias y además una coincidencia de encuentro entre las dos personas, por lo que la realización del comercio por la vía del trueque era casi imposible. Esa imposibilidad, terminaría por convertirse en un serio límite a la división del trabajo, y al proceso evolutivo que se origina producto de este fenómeno que es una de las bases del sistema económico.

Menger está deduciendo, que es el método que considera correcto para la ciencia económica, y lo está aplicando al vasto conocimiento por la vía del trueque, que es una de las características que debería poseer un economista y nos propone:

Lo cierto que este conocimiento no se produce nunca al mismo tiempo en todos los miembros de un pueblo. Al contrario, en las primeras etapas, sólo un reducido número de sujetos económicos advierte las ventajas se derivan cuando, al no poder intercambiar sus mercancías por bienes de uso directo, o cuando este intercambio es muy inseguro, aceptan otras mercancías con mayor facilidad de venta.

Esta ventaja es, de suyo, independiente del reconocimiento generalizado de una mercancía como dinero, ya que este intercambio supone siempre y bajo cualquier circunstancia un considerable paso adelante hacia la meta perseguida por todo individuo económico, a saber, hacerse con los bienes de uso que le son necesarios. ${ }^{5}$

Por supuesto, Menger está apelando a otro de los pilares de lo que conforma la Escuela Austriaca de Economía, el conocimiento que es desigualmente distribuido, pero que puede ser trasmitido por la colaboración que determina la vida en sociedad. Eso también condiciona que los distintos pueblos usen como moneda diversas mercancías, y el economista austriaco usará varios ejemplos para dejar en claro esta propuesta.

\footnotetext{
4 Menger, C. (1871), p. 319.

5 Menger, C. (1871), p. 323, subrayado en el original.
} 
Para Menger era definitivamente distinta su deducción del proceso que originó el dinero y lo que los historiadores explican sobre el fenómeno:

[...] El origen del dinero (que debe distinguirse del subgénero de las monedas acuñadas) es, como hemos visto, del todo natural y por consiguiente, sólo en muy contados casos puede atribuirse a influencias legislativas. El dinero no es una invención estatal ni el producto de la autoridad estatal es, pues, un factor ajeno al concepto del dinero. El hecho de que algunas mercancías alcancen la categoría de dinero surge espontáneamente de las relaciones económicas existentes, sin que sean precisas medidas estatales. ${ }^{6}$

El planteamiento de Menger es deductivo como se afirma arriba y eso no se entiende a simple vista, pero para descifrar a Menger es necesario comprender que sus escritos están dirigidos, además de, a exponer sus ideas, para ofrecerlas en contraste a la Escuela Histórica Alemana, que al contrario de su propuesta se fundamenta en una metodología inductiva y, sobre todo, una economía que esté sometida al nacionalismo del estado alemán, el cual está conformándose en el momento histórico de Menger.

Keynes abogaba por la propuesta contraria y, en su Tratado del Dinero, ${ }^{7}$ hizo la descripción de lo que él consideraba que era el origen del dinero y lo vinculó de un inicio a la existencia de un gobierno que lo define, él mismo cita a Knapp ${ }^{8}$ como la fuente de la teoría que expone. De hecho, Knapp expone que el origen del dinero procede de una deuda que contrae el gobierno con los particulares y que él le concede valor por lo que comienza a usarse como dinero. Pero Knapp también pertenece al historicismo

\footnotetext{
${ }^{6}$ Menger, C. (1871), pp. 324-326.

7 Keynes, J.M. (1930) Tratado del Dinero (ed. Abreviada), Editorial Aosta, C.A. Madrid 1996.

8 Knapp, G.F. (1905). The State Theory of Money. Macmillan, London, citado por Lapasvitsas, C. (2003): Money as «Universal Equivalent» and its origin in Commodity Exchange. Department of Economics School of Oriental and African Studies. University of London, está disponible en internet en la siguiente dirección: http:/ / www. soas.ac.uk/economics/research/workingpapers/file28848.pdf [18/03/2011].
} 
alemán y pretende imprimirle al gobierno la facultad de ser el creador del dinero de una manera intuitiva, de hecho, su teoría es conocida como la del dinero Cartalista o nominalista, y fundamenta el establecimiento de dineros nacionalistas y con carácter soberano.

Keynes como referimos fundamenta su conocimiento en esta propuesta y de una manera muy breve pero no menos envolvente, en el corto primer capítulo de su obra. En ella habla de ladrillos cocidos, incluso llega a nombrar la Atlántida, el Edén y las Hespérides, para terminar afirmando:

Cuando los reyes de Lidia acuñaron monedas por vez primera, puede que se tratara de un simple certificado de ley y peso o un mero acto de ostentación propio de los descendientes de Creso o sus vecinos de Midas. La estampación de unas piezas de metal con una marca fue exactamente una demostración de vanidad local, patriotismo o propaganda sin mayor alcance. [...] No era necesario, por tanto, que los talentos o siclos fueran acuñados; era suficiente que las unidades fueran creadas por el Estado, que era quien definía (con el derecho a variar su definición de cuando en cuando) el peso y ley de la plata que, a efectos legales, bastaba para satisfacer una deuda o un pago ordinario, expresado en talentos o siclos de plata. ${ }^{9}$

Para Keynes el dinero existe antes de la primera emisión monetaria, pero como decreto o como orden del gobierno que le da cuerpo a esta institución, por esa razón comienza su explicación por el Dinero-Cuenta, por lo que surge en la emisión de documentos que permiten cancelar una compra, o una deuda en el futuro.

Fundamentalmente Keynes quiere desligar la creación del dinero de un proceso de mercado, y prefiere abrazarse de la teoría historicista de Georg Friedrich Knapp afirmando que el dinero es una creación de la ley, por esta razón desprecia el pasaje de Heródoto. ${ }^{10}$

\footnotetext{
9 Keynes, J.M. (1930), p. 36.

10 Keynes, J.M. (1930), p. 30.
} 
Recientemente Charles Goodhart ${ }^{11}$ de la London School of Economics publicó un trabajo en el cual mantiene la división tradicional de criterios, para él, al igual que para muchos economistas y otros tantos historiadores, Keynes representa la posición Cartalista del dinero, es decir la de creer que el dinero es una institución inventada por algún gobierno en la noche de los tiempos y Menger, al igual que quienes defienden el origen del dinero evolutivo, son denominados Metalistas. El análisis de Goodhart está destinado a darle una explicación a los sistemas como el del Euro y justificar el mantenimiento de un Banco Central. No es realmente una pieza que permita discriminar si el dinero tiene alguno de los dos orígenes, puesto que intencionalmente Goodhart tiene debilidad Cartalista.

De la misma manera en la que Keynes expresa sus temores por la conversión del dólar en moneda de cambios internacionales, ${ }^{12}$ Goodhart siente preocupación por la adscripción de Europa al Euro y prefiere el mantenimiento de una moneda nacional. Por eso, coloca en una única posición ${ }^{13}$ a aquellos que no son cartalistas, tildándolos de Metalistas.

Sin embargo, el origen del dinero es aún anterior a esto, puesto que el análisis de Knapp está también influido por la necesidad de un dinero nacional y de otorgarle al gobierno la potestad de determinar qué cosa es dinero y qué valor debería poseer.

Hudson también aporta sus ideas al debate, buscando razones históricas para el orígen del dinero en un trabajo de 2003,14

11 Goodhart, Charles: «The two concepts of Money: implications for the analysis of optimal currency areas», European Journal of Polítical Economy, Vol. 14, pp. 407432, March 1998.

12 Hay que observar el Tract of Money (1932) en el cual Keynes manifiesta estos temores que luego van a ser el causal de su plan en la fundación del Fono Monetario Internacional en 1944. Ver en Aguirre, José A.: El Capitalismo y La Riqueza de las Naciones. Vicisitudes de la teoría económica moderna, Unión Editorial, Madrid 2009, pp. 323 ss.

13 Esto es abiertamente injusto, no todas las posiciones favorables al patrón oro son anticartalistas, ni todos los que abogan por una moneda adscrita al oro son anticartalistas, esto es una simplificación, para despistar a los que leen.

${ }_{14}$ Hudson, Michael, The Creditary/Monetarist Debate in Historical Perspective Publicado en 2003, como «The Cartalist/Monetarist Debate in Historical Perspective,» in Edward Nell and Stephanie Bell eds., The State, The Market and The Euro, London: 
en donde sorprende, debido a que revive las tesis historicistas que abogan por un dinero gubernamental, pero insiste en colocar juntos a todos los que llama monetaristas que es, podríamos decir, un término más de los que usan los que se autodenominan «de izquierda» para llamar a los que según ellos les adversan.

\section{¿QUÉ DICE LA HISTORIA?}

Los historicistas tienen su finalidad en la historia alemana y fueron combatidos por Menger, quien comprendió que no eran economistas y que habían colocado en debilidad al pensamiento germano para enfrentar el desarrollo de políticas económicas, ellos con sus aficiones por el Gobierno que denominaban rimbombantemente Estado, contribuyeron al establecimiento de los Karteles y, por supuesto colocaron al pensamiento económico alemán en posición de debilidad para enfrentar el período de la primera postguerra (que se denomina la hiperinflación alemana). Por supuesto, las ideas de Bruno Hildebrand, Karl Knies y Wilhelm Roscher, así como las de Sombart, resuenan en quienes critican las políticas liberales, pero no llegan más allá, para ver los efectos que sus errores de concepto, aplicados a la teoría y la historia, ocasionaron en el pueblo alemán y en otros en los que influyeron. En Inglaterra hubo una profunda influencia de este grupo entre Marshall y sus discipulos, incluyendo a Keynes.

Pero es necesario buscar la documentación para entender el proceso histórico e interpretarlo. Hay en Historia unos enunciados que son casi tomados como un dogma de fe, sin embargo, es necesario revisarlos para dar respuesta a la inquietud que determina la razón de este artículo. El primero de estos mitos afirma que la escritura marcó la salida de la prehistoria y esa es una verdad relativa, debido a que las primeras civilizaciones que tuvieron escritura no lo hicieron por razones históricas o, mejor dicho,

Edward Elgar, 2003. Se consigue en internet en la siguiente dirección: http:/ / michaelhudson.com/2003/03/the-creditarymonetarist-debate-in-historical-perspective/ [19 de marzo de 2011]. 
dichas civilizaciones no tenían preocupaciones históricas, tal es como en Egipto o en las civilizaciones Mesopotámicas. Estas civilizaciones tenían inquietudes comerciales y religiosas y sus documentos versan sobre eso, por lo que puede afirmarse que la creación de la escritura persigue un fin comercial, financiero y religioso, antes que un fin histórico. La historia es una preocupación posterior y la civilización que está atada a esta preocupación es la Griega y, de manera tangencial, debido a su ideal de «pueblo elegido» se puede añadir, haciendo esta salvedad, el caso de los hebreos. Éstos tenían una preocupación histórica, pero no como objeto de investigación, sino como medio para ratificar su diferenciación frente a las otras sociedades del oriente próximo, a los que los unían lenguaje y otras costumbres. Puede ser complicado afirmar que eso sea historia, interpretación o conocimiento histórico por supuesto, la idea de crónicas como las expone el antiguo testamento no buscan entender el proceso de los hechos, sino antes bien exponer el por qué ese pueblo puede afirmar que es el pueblo elegido, sin una vocación claramente histórica. Por eso las sagradas escrituras no siguen referencias temporales. $\mathrm{Ni}$ puede usarse como documento histórico, a menos que se quiera hacer una historia social de ese pueblo que se denomina Judío.

Otra es la realidad del mundo Griego. De hecho, Herodoto es el iniciador de este arte que fue para los griegos la historia, y lo hace colocándole al texto ese mismo nombre, marcando definitivamente qué es el conocimiento histórico para quienes le sigan en esta disciplina. Entendiendo que para los griegos, la historia no termina de estar claro si es una ciencia o un arte. En su libro, refiere que no son los griegos quienes inventan el alfabeto:

Pero estos fenicios llegados con Cadmo, a los cuales pertenecían los gefireos, cuando se establecieron en el país introdujeron entre los griegos muchas cosas dignas de saberse, y principalmente la escritura, que, por lo que a mi parece, los griegos antes no conocían, y concretamente aquella que hoy todavía usan todos los fenicios. Con el transcurso del tiempo, juntamente con los sones modificaron también la secuencia de los signos. ${ }^{15}$

15 Herodoto: (c. 425 a.C.) Historia, Cátedra Letras Universales, 3.ㄹ ed., Madrid, 2004, L.V. §58, p. 517. 
Su Historia, probablemente escrita en el 425 a.C., comienza con el relato de los Lidios, describiendo hechos que ocurrieron aproximadamente en el siglo VI o VII a.C. y esto es importante, debido a que no se puede afirmar que la historia comienza con la escritura. ${ }^{16}$ De hecho, la escritura comenzó aproximadamente cuatro milenios antes con los Sumerios y no es sino en el siglo IV a. C., es decir en el primer milenio, el momento cuando se está escribiendo la primera historia. Los griegos conocen la escritura aproximadamente en el siglo XV o XVI a.C. y es casi un milenio después que se está escribiendo la historia de Herodoto y esa historia, ha hecho caso omiso de casi todas las civilizaciones mesopotámicas, que antecedieron a los lidios, quienes son en el momento histórico una suerte de mezcla de griegos con mesopotámicos, o fenicios.

Herodoto busca que entendamos que ellos son diferentes a los griegos, sienten vergüenza de la desnudez, pero permiten la disipada moral de sus hijas, regalan a sus hijos y son adictos al juego que han inventado. Pero estos reyes Lidios tienen una mina que les ha hecho inmensamente ricos. Eso les va a permitir ser los primeros en realizar una emisión monetaria. ${ }^{17}$

Pero caben algunas preguntas, si la moneda no existía antes de la primera emisión hecha por Creso entonces ¿de qué habla Keynes cuando se refiere a que esta emisión es un acto meramente simbólico? ¿Es qué la moneda existe desde antes? ¿Qué ocurre con el trueque del cual se habla en la historia económica universal? ¿Cómo queda la afirmación de Menger de la evolución institucional? Pues el objetivo es tratar de dar respuesta a estas interrogantes.

El dinero existe desde antes, tal cosa puede deducirse de la lectura de un documento anterior a la Historia de Herodoto, un documento mesopotámico que habla de las relaciones comerciales y civiles de la civilización babilónica. El Código de Hammurabi expone:

49.- Si uno ha recibido en préstamo dinero de un comerciante y ha dado al negociante un campo cultivable de trigo o de sésamo

16 Con la escritura, ocurre igual que con el dinero, son instituciones que surgen de manera espontánea, no planificada ni premeditada, son producto de la evolución del conocimiento, para satisfacer una determinada necesidad del humano en su vida en sociedad.

17 Heródoto: Historia L. I, pp. 69-122. 
diciéndole: «Cultiva el campo, cosecha y toma el trigo o el sésamo que habrá allí» cuando el cultivador haya hecho venir el trigo o el sésamo en el campo, en el momento de la cosecha el propietario del campo tomará el trigo o sésamo que exista en él y dará al negociante trigo por el dinero con los intereses que tomó del negociante y el costo del cultivo del campo.

Esta es la ley n. -49 y no constituye la primera vez que Hammurabi nombra al dinero, pero es interesante para observar la existencia de préstamos, por lo que debe haber dinero, como dice el mismo párrafo, y además cálculo de intereses, esto podría proponer una nueva pregunta, debido a, que para que se pueda dar un préstamo a intereses, los participantes deben tener alguna medida del tiempo (calendario) alguna unidad de cuenta (dinero), la necesidad del fenómeno de la escritura orientada a la contabilidad y a las finanzas, así como el uso de la práctica de la matemática. Eso es casi una coincidencia para todas las civilizaciones, al menos las que surgen en el oriente próximo.

Pero Hammurabi es excelente para entender los procesos de mercado y para acercarse a los fenómenos monetarios. Debido a que este rey de Babilonia, intentó fijar precios en su legislación pero, mejor aún, nos termina dando a entender que la moneda era una combinación de peso y metal, así vemos expresiones como siclos de plata, minas de plata, gur de plata; aunque era posible pagar en otra especie, como el trigo y aunque se le nombra, es notable que el oro es usado de manera menos frecuente. Entonces, la pregunta es ¿qué tiene que ver el gobierno con una transacción en la cual la moneda es un peso, de metal? Probablemente nada, quizá muy poco, que se limita al intento de Hammurabi de establecer precios, pero no la calidad o la cantidad de moneda. Prueba de ello es la ley no 89 que reza:

89.- Si un banquero dio a interés trigo o plata, tomará 100 QA como interés por GUR de trigo y sobre la plata, por siclo de plata, tomará el sexto más 6 SHE como interés. ${ }^{18}$

18 Tanto el Qa, como el Gur, de la misma forma que el She son medidas de peso, lo que sigue acentuando que se trata de mediciones de peso de mercancía, sea esta metal precioso o trigo. 
Para los que pretenden interpretar el dinero como un certificado de deuda que podía ser transferido, es difícil probar su existencia, porque en ningún momento definen el dinero como eso, $\mathrm{y}$ si es porque esa forma de dinero es de uso generalizado, resulta aún más difícil, debido a que eso significaría que los sumerios, acadios y babiliónios conocieron los instrumentos financieros antes que la moneda mercancía y que eran capaces de un nivel de abstracción simbólica excepcional, pero surge otra duda ¿si eso era el dinero cuando pagaban en exceso qué les daban de vuelto? ¿Otra tablilla? ¿Había un mercado secundario de tablillas?

Pero anterior a las leyes de Hammurabi son las leyes sumerias, que hoy conocemos gracias a las investigaciones de muchos arqueólogos, incluso en universidades Hispanas que traducen y publican estas tablillas, pertenecientes al tercer milenio antes de Cristo, en ellas hay algunas penas pecuniarias y eso es interesante, por ejemplo:

Si un hombre repudiaba a su primera esposa, pagaba 1 mana de plata. ${ }^{19}$

Como se puede observar no propone el pago en tablillas o en alguna suerte de dinero fiduciario o dinero crédito. Tenemos de nuevo la combinación de metal y peso, por lo que podríamos afirmar que hasta ahora, la antigua Mesopotamia le da la razón a Menger en que el establecimiento de una moneda es un proceso de mercado, debido a que no habla de calidades o de un dinero institucional. Aunque Hammurabí, el rey babilónico, está intentando establecer precios e incluso decretarlos en esta legislación, no estamos seguros que la ley se cumpla, y como en los países en los que se controla precios o mercados, en los cuales surgen inmediatamente mercados negros o economías informales, en las que si se dan las relaciones de acuerdo a la oferta y la demanda. Sin embargo, retomando a Herodoto encontramos un pasaje sin igual, que los historiadores denominan el Trueque Mudo, hay que entender

19 Molina, Manuel (2000) La ley más antigua textos legales sumerios, Ediciones de la Universidad de Barcelona, Barcelona, p. 70. Un Mana o una Mena es el equivalente a aproximadamente 500 gr. de Oro. 
que los historiadores no son economistas y en esta disciplina, aunque tengan especialidad en historia económica, muestran sus debilidades.

Los cartagineses cuentan también lo siguiente: a poniente de Libia hay aún un país de hombres más allá de las Columnas de Heracles. Cuando ellos llegan allí, descargan sus mercaderías y las colocan alineadas en la playa. Luego regresan a sus naves y encienden fuegos que despiden mucha humareda. Cuando los nativos advierten el humo, se llegan hasta el mar. Colocan oro al lado de las mercancías y se alejan mucho de ellas. Los Cartagineses acuden allí desde sus naves y observan. Si el oro les parece suficiente lo toman y se van; de lo contrario, suben otra vez a sus naves y observan. Los nativos se acercan y añaden más oro, hasta que parezca suficiente. ${ }^{20}$

El párrafo explica cómo hacían comercio los Fenicios con los primitivos habitantes de la actual costa marroquí, y aunque se insista en la existencia de un trueque, es una operación de compra venta, con la única moneda que existe, es decir el metal y su peso. Permite además, observar el comercio como una relación cataláctica pura. Es decir como una relación de oferta y demanda. Estos antiguos marroquíes no entregan dinero crédito o dinero fiduciario, sino oro y tanto los primitivos marroquíes como los fenicios deciden cuando están satisfechos en este regateo mudo.

II

PENSANDO LA HISTORIA COMO ECONOMISTA

Pensando en la propuesta keynesiana, si se trata de un comercio en el cual las dos partes no se hablan y la única comunicación es simbólica ¿quién podría afirmar que el comercio está certificado por un Gobierno que legisla la calidad del oro, o el peso que dicho metal tiene? ¿Cabe preguntarse aquí si se trata de otra de las habilidades persuasivas del prof. Keynes para convencernos de sus falacias?

${ }^{20}$ Heródoto: Historia L. IV, §196, p. 480. 
Como puede verse lo que llaman algunos historiadores Trueque $M u d o$ es realmente otra forma de comercio tradicional, y que debería denominarse Comercio Mudo. Pero sobre todo, muestra que el trueque es en realidad una excepción y no la norma, que probablemente fue posible en algún momento en lo que se da en denominar prehistoria, cuando el hombre vivía en tribus nómadas y se encontraba con otra tribu que tenía mercancías distintas (ganados, pieles, herramientas, etc.) En general, no estaba definido ningún patrón monetario y probablemente aunque los humanos conocían los metales y las piedras preciosas, estas mercancías no eran consideradas abiertamente dinero, porque ese es un paso en el proceso evolutivo que requería la sedentarización y la división del trabajo, que es producto de una etapa en la que se hizo necesario el establecimiento de la ciudad y por supuesto, de lo que llamamos civilización y que, como se expuso antes, tiene necesidades como la existencia de calendario, dinero y escritura, que sólo es posible para las tribus sedentarias.

Para acercarnos con otro ejemplo, Homero en su Iliada hace hablar a Aquiles, con estas duras palabras a Hector, quien está agonizando:

Mirándole con torva faz, le contestó Aquileo, el de los pies ligeros: No me supliques, iperro!, por mis rodillas ni por mis padres. Ojalá el furor y el coraje me incitaran a cortar tus carnes y a comérmelas crudas. ¡Tales agravios me has inferido! Nadie podrá apartar de tu cabeza a los perros, aunque me den diez o veinte veces el debido rescate y me prometan más, aunque Príamo Dardánida ordene redimirte a peso de oro; ni aun así, la veneranda madre que te dio a luz te pondrá en un lecho para llorarte, sino que los perros y las aves de rapiña destrozarán tu cuerpo. ${ }^{21}$

De nuevo se habla de precio, y sobre todo de su medida en peso y tipo de metal. Si eso no es suficiente, en el Canto XIX de la misma obra, dice de Ulises, cuando ejecutaban las exequias de Patroclo, cuando Aquiles abandona su cólera:

${ }^{21}$ Homero (c. s. IX a.C.) La Iliada. Canto XXII §344-354 en: http://www.iliada. com.mx/Texto_y_comentarios/CANTO_XXII.html [17/marzo/2011]. 
[...] Odiseo iba delante con los diez talentos de oro que él mismo había pesado $[\ldots]^{22}$

Lo importante aquí es que, Ulises con toda la brillantez de su imaginación no inventó el talento, ni la moneda, y por su parte, se siente partícipe de una práctica generalizada de la humanidad antigua, ratificando el uso de peso y metal, aunque la expresión talento va a ser utilizada después para designar a algunas monedas en la antigüedad, en este caso debe ser entendida como una unidad de peso que está en franca relación con el metal. La expresión talento es usada muchas veces, antes y después de este verso, y también es común en el texto de la Odisea, tanto para referirse a la habilidad de un individuo, como para referirse a un determinado peso de metal.

Se podrían hacer unas nuevas preguntas. ¿Para qué se pesa un dinero? Si existe el emisor ¿Se desconfía de la calidad del mismo? ¿No es suficiente el aval del mismo para aceptar que eso es un talento? Sabemos que es poesía, pero probablemente también la creencia que el dinero crédito antecedió al dinero mercancía sea una meta-realidad.

Por todo esto, se podría interpretar que el dinero es como lo dice Menger producto de un proceso evolutivo, no azaroso, pero si espontáneo; en el cual a una mercancía se le convierte por acuerdo general, no legislativo, ni compulsivo en un bien adaptado para realizar comercio, eso ocurre en las etapas primigenias de la historia, sin participación del Gobierno o lo que convencionalmente se da en llamar Estado. Ese dinero incial era una manifestación más de la propiedad privada, por lo que era de orígen privado, puesto que se trataba de una institución natural.

Aunque afirme que el acto de la primera acuñación no tiene la relevancia, se trata de otro giro habilidoso de la prosa de Lord Keynes, debido a que la acuñación de Lidia representó el momento histórico en el cual el Gobierno se arrogó el derecho de determinar qué mercancía y de qué calidad y peso debería ser considerada dinero. Este acto por demás injusto, le permitió establecer

${ }^{22}$ Homero, Op. cit. Canto XIX §238 en: http://www.iliada.com.mx/Texto_y_ comentarios/CANTO_XIX.html [17/marzo/2011]. 
el señoreaje, así como la posibilidad de devaluar, incluso, la cruel práctica de la sustitución monetaria a la que se dio pie en China con la invención de la moneda de papel y establecer, de esa forma, nuevas y variadas formas de expropiación de la propiedad privada.

\section{REFERENCIAS BIBLIOGRÁFICAS}

Aguirre, J.A. (2009): El Capitalismo y La Riqueza de las Naciones. Vicisitudes de la teoría económica moderna, Unión Editorial.

GOODHART, CH. (1998): «The two concepts of Money: implications for the analysis of optimal currency areas», European Journal of Political Economy, Vol. 14, pp. 407-432, March.

Herodoto (c. 425 a.C.): Historia, Cátedra Letras Universales, 3. ed., Madrid, 2004.

Homero (c. s. IX a.C.): La Iliada en: http: / / www.iliada.com.mx/ Texto_y_comentarios/CANTO_XIX.html [17/marzo/2011] Hudson, M. (2003): The Creditary/Monetarist Debate in Historical Perspective Publicado en 2003, como «The Cartalist/Monetarist Debate in Historical Perspective,» in Edward Nell and Stephanie Bell eds., The State, The Market and The Euro, London: Edward Elgar. Se consigue en internet en red: http:/ / michael-hudson.com/2003/03/the-creditarymonetaristdebate-in-historical-perspective/ [19 de marzo de 2011].

Keynes, J.M. (1930): Tratado del Dinero (ed. Abreviada), Editorial Aosta, C.A. Madrid 1996.

LAPASVITSAS, C. (2003): Money as «Universal Equivalent» and its origin in Commodity Exchange Department of Economics School of Oriental and African Studies. University of London, está disponible en red: http://www.soas.ac.uk/ economics/ research/workingpapers/file28848.pdf [18/03/2011].

Menger, C. (1871): Principios de Economía Política, Unión Editorial, 2..$^{\text {a }}$ ed., Madrid, 1997.

Molina, M. (2000): La ley más antigua textos legales sumerios, Ediciones de la Universidad de Barcelona, Barcelona. 